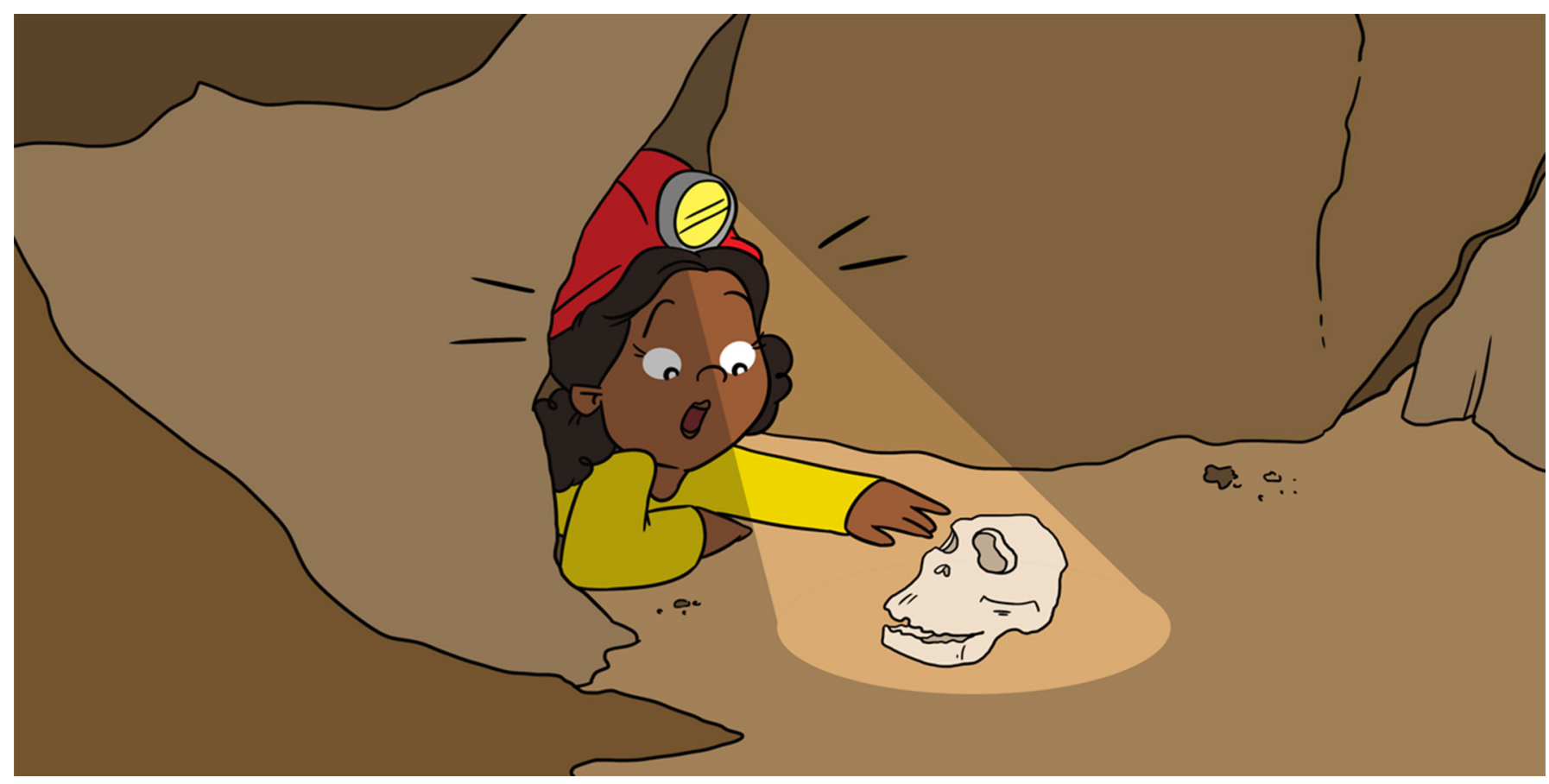

\title{
MEET NEO: YOUR DISTANT COUSIN?
}

\section{Becca Peixotto ${ }^{1,2^{*}}$ and Marina C. Elliott ${ }^{1}$}

${ }^{1}$ Evolutionary Studies Institute, University of the Witwatersrand, Johannesburg, South Africa

${ }^{2}$ Center for the Exploration of the Human Journey, Perot Museum of Nature and Science, Dallas, TX, United States

YOUNG REVIEWER:

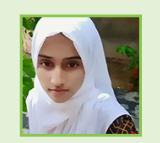

SAMEEN

AGE: 14
Have you ever wondered about your extended family? Paleoanthropologists - scientists who study the history of the human family-discovered bones in South Africa belonging to a species of human relative they call Homo naledi. The bones were located deep underground in the Rising Star Cave, in a chamber that is difficult to access. Scientists gave the nickname Neo to one of the most complete skeletons they found. The bones of Neo and other Homo naledi individuals are helping us understand more about the family history of our own species, Homo sapiens. This article describes how Neo was found and what we have learned about him and his species, Homo naledi. It will also tell you what research scientists do to solve mysteries like how old Neo was when he died and how his bones got into the cave.

\section{INTRODUCTION}

Many people like to learn about their family histories: what their parents, grandparents and even great-grandparents were like and 
PALEO-

ANTHROPOLOGIST

Scientists who study ancient humans and their relatives.

\section{HOMININS}

A group of primates that includes humans and all of their extinct ancestors and relatives.

where they came from, or if they are related to an important historical person. Or, they might like to know if a physical feature or behavior they share with an aunt or cousin was passed down from a common relative. Scientists called paleoanthropologists are interested in the family history of Homo sapiens, the species to which all people living today belong. Unlike paleontologists who study the remains of dinosaurs, paleoanthropologists study the remains of hominins. Hominins are a group of primates that includes humans and all our extinct ancestors and relatives, most of whom lived in the last 6-7 million years. Like someone trying to trace a family tree, paleoanthropologists try to figure out which of the extinct hominins might be our direct ancestors and which are just distant cousins. These scientists also try to understand what the hominins ate, where they lived, how they died, and other things about the lives of these ancient relatives.

One area that has been very important for understanding our human past is the Cradle of Humankind. It is a United Nations Educational, Scientific, and Cultural Organization (UNESCO) World Heritage site near Johannesburg, South Africa. The region is riddled with caves and is special to paleoanthropologists because lots of hominin fossils have been found there over the last 100 years. In 2013, cavers exploring the Rising Star Cave discovered bones in a chamber deep underground (Figure 1). Paleoanthropologists later identified the fossils as a previously unknown species of extinct hominin. They named the species Homo naledi [1]. One particular Homo naledi skeleton is known as Neo.

\section{WHO WAS NEO?}

Neo (nay-oh) means "gift" in SeSotho, one of the 11 official languages of South Africa. Neo is the nickname scientists gave to a partial skeleton of an adult Homo naledi, found in the Lesedi Chamber of the Rising Star Cave. Scientists recovered bones from almost every part of Neo's body except his lower legs and feet (Figure 2) [2].

Neo's bones are large compared to other Homo naledi individuals. Because male primates tend to be bigger than females, scientists think Neo was probably a male. And since his bones are fully grown and his teeth are worn, scientists know Neo was an adult when he died. Paleoanthropologists do not yet know how long ago Neo himself lived, but tests on other Homo naledi fossils show the species existed at least 236,000-336,000 years ago [3]. These dates were obtained by analyzing teeth and geological formations found in the cave. Neo may have lived at that time too. 


\section{Figure 1}

Location of the Cradle of Humankind in Africa (upper right). A diagram of the Rising Star Cave showing the main entrance (blue arrow), the Dinaledi Chamber (orange circle), and the Lesedi Chamber area (blue circle)
Figure 2

(A) The skeleton of $\mathrm{NeO}$ from the Lesedi Chamber. Photo by John Hawks. (B) An artist's reconstruction of what Neo may have looked like in life. The reconstruction combines scientific understanding of the anatomy and body proportions from the bones with educated guesses of hair, skin, and eye color.

Sculpture by Élisabeth Daynès. Photo by Perot Museum of Nature and Science.
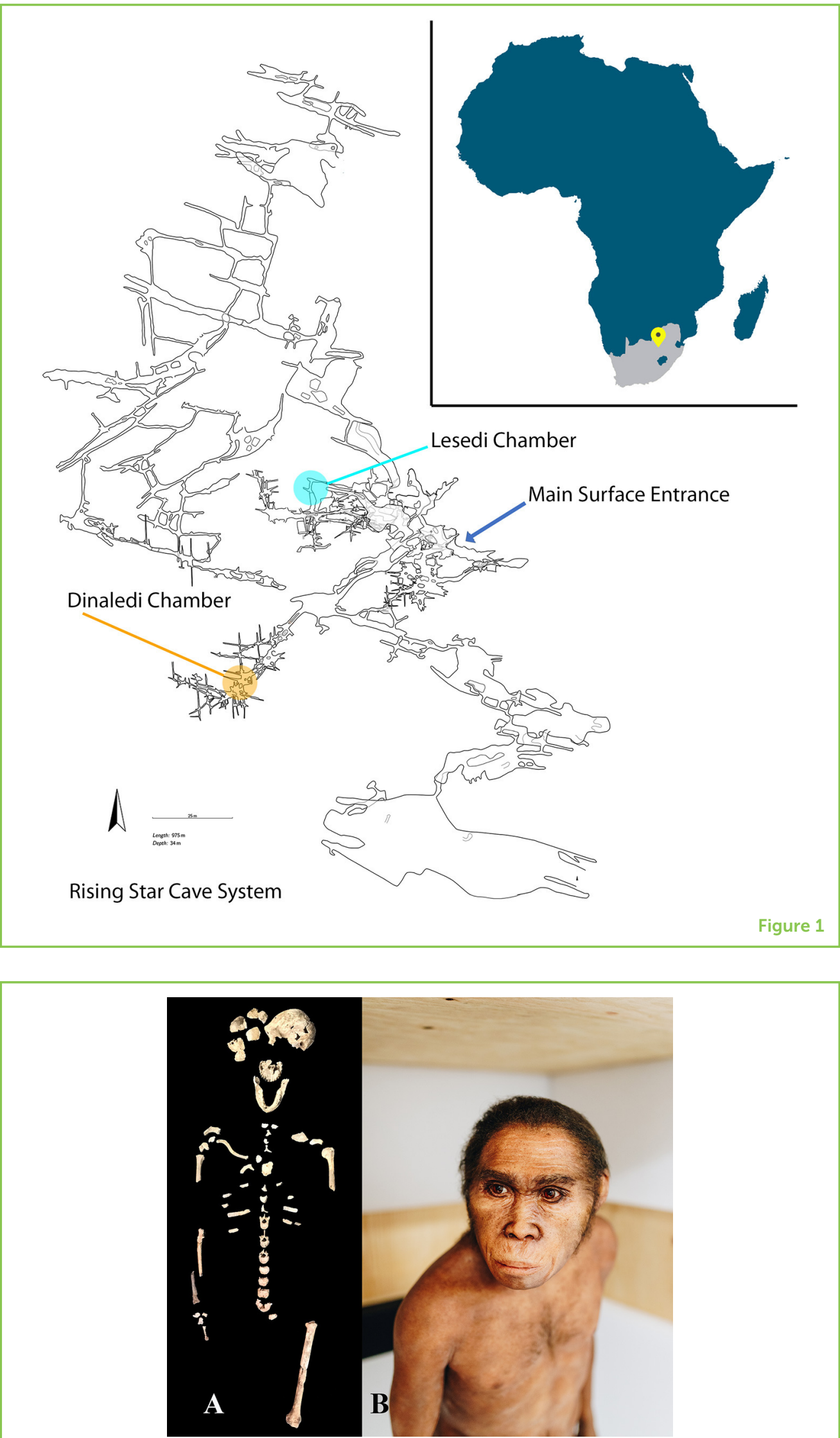

Figure 2 


\section{HOW WAS NEO FOUND?}

Neo was the third discovery made by two South African cavers, Rick Hunter and Steven Tucker, in the Rising Star Cave in 2013. First, they discovered a very narrow fissure leading to a chamber that was not on any of the maps. That chamber became known as Dinaledi Chamber (meaning "chamber of stars") [1].

There, the cavers discovered something else-a scattering of bones on the floor and a partly buried skull fragment. They alerted paleoanthropologist Lee Berger, who organized a team to excavate the bones. The six women excavators (including the two authors of this paper) needed to climb and crawl through very tight and difficult passages to recover the fossils. Working on their hands and knees with toothpicks and paintbrushes, the excavators recovered more than 1,500 fossils in just a few weeks. After studying the bones, scientists determined they belonged to an extinct species of ancient hominin that had never been seen before. They named the species Homo naledi ("naledi" means "star") [1].

During the excavations, Rick and Steven continued to explore the Rising Star Cave. That is when they made their third discovery: more Homo naledi fossils in another chamber. In total, three individuals were found in this area, now named the Lesedi Chamber (Lesedi means "light"). Neo, also known by his scientific name LES-1, was the first, and most complete skeleton found there [2].

\section{HOW DO WE KNOW NEO IS HOMO NALEDI?}

All humans alive today are Homo sapiens. "Homo" means "human" in Latin and refers to the genus, a broad category that includes multiple species who share certain characteristics. "Sapiens" means "wise" and refers to the particular species that all humans on the planet belong to. Another group of hominins, in the genus Australopithecus, shared features with modern humans but also had many physical differences. Lucy is the nickname for one famous Australopithecus afarensis female discovered in Ethiopia in 1974. Her scientific name is AL 288-1 [4].

After the bones were excavated from Rising Star Cave, they were cleaned and analyzed in a lab. Scientists compared the new fossils to those of species that had already been described, to see if they looked similar or different. Some bones of Homo naledi looked similar to known Australopithecus or Homo species, but many were totally different. Since no previously known species was a good enough match, the scientists knew they were looking at something new. 


\section{Figure 3}

From top to bottom, Neo's right collarbone (clavicle) shown from the top, front, bottom, and back. The break in the middle of the bone indicated by blue arrows, happened after Neo died. The dark staining on the bone is from iron and manganese and helps taphonomists understand how the bone was buried in the sediment in the cave. Photo by John Hawks.

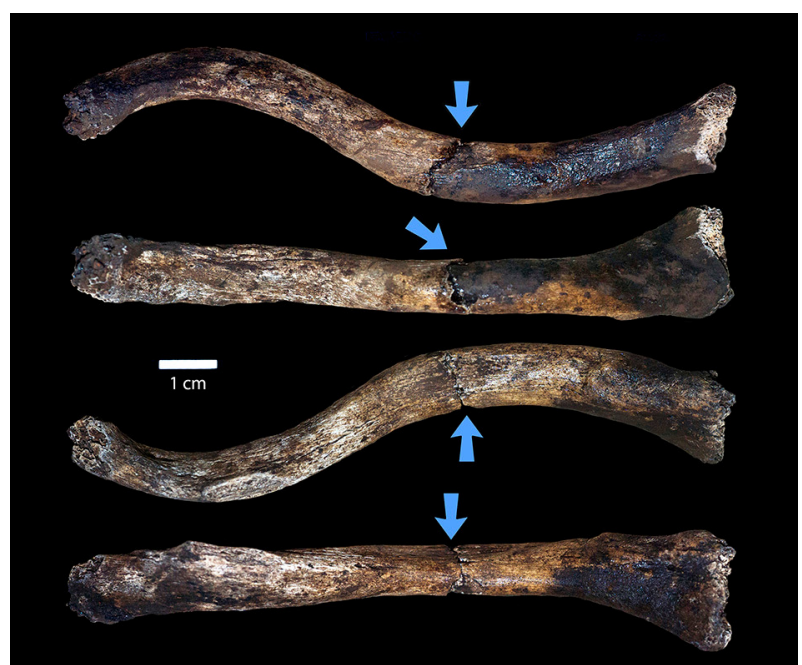

Figure 3

\section{HOW DID NEO'S BONES GET IN THE CAVE?}

After the scientific team examined the shape of Neo's bones, they looked at the condition of the fossils to determine how they got in the cave and what might have happened to them afterwards. Taphonomists are scientists who study what happens to an animal's body and bones after it dies.

One of the first things a taphonomist looks for is breaks on a bone. From the way a bone is broken, the scientists can tell whether an animal fell into the cave when it was still alive, or after it died. For Neo, all the breaks appeared to have happened after death so the taphonomists do not think Neo fell or was pushed into the cave (Figure 3).

Taphonomists also look for cracks or damage on the surface of bones. Cracks or damage would indicate the bones were exposed to weather or sun for a long time after the skin and flesh decomposed. The taphonomists did not see these signs on Neo's bones, so they think his body was already in the cave before it decomposed.

Next, taphonomists look for marks that might tell them if a predator or scavenger chewed on the bones. The scientists found tiny tracks from insects on Neo's bones, but no teeth or claw marks from other animals. As a result, the scientists do not think Neo was killed or dragged into the cave by a predator or scavenger.

Scientists then considered the possibility that Neo was washed into the cave during a flood from the nearby river. Rushing water causes bones to appear smooth, rounded, or polished, similar to what happens to a pebble in the river. The taphonomists could not find any evidence that 


\section{HYPOTHESIS}

A testable idea or suggestion to explain an observation. the bones were moved by flowing water, so they do not think Neo's bones were washed into the cave by a flood.

When scientists see something in nature, they propose a hypothesis - an idea or suggestion to explain what they observe. They then test their hypothesis against new observations or evidence, and adjust their explanation to improve it. Observing the evidence in the Lesedi Chamber, the Rising Star taphonomists determined that Neo had not fallen into the cave, his bones had not been on the surface for very long after he died, he was not dragged into the cave by another animal, and his bones were not washed in by a flood. The scientists saw the same evidence in the bones from the Dinaledi Chamber too. The team then proposed a hypothesis that they felt best fit the evidence they were seeing in both chambers: Neo's body and those of the other Homo naledi individuals were placed in the cave after they died $(1,2)$.

\section{MORE QUESTIONS TO ASK}

There are still many things about Homo naledi that the scientists do not know, and lots of new questions to ask. To help with these questions, excavators keep digging in the Dinaledi and Lesedi Chambers and finding more fossils. Geologists and cavers continue to search the Rising Star Cave looking for new passages and learning about how the cave formed. Some researchers are studying the bones of Homo naledi to see how they grew and aged or to see how they moved. Others are examining the teeth to learn what Homo naledi ate. This information helps the team understand how Homo naledi lived in its environment. And the taphonomists are still looking for clues about how Neo and his relatives might have died.

One big question scientists are still trying to answer is how Homo naledi is related to our own species, Homo sapiens, and other hominins. Family histories can be very complicated, even with good records of when and where individuals were born. With only bones to work with, it is difficult to determine whether Neo and his kind are direct ancestors of ours, or more like distant cousins. However, we are connected, one thing is certain: Homo naledi is a fascinating-and still mysterious-member of the greater human family, one that may help us better understand ourselves.

\section{AUTHOR CONTRIBUTIONS}

$\mathrm{BP}$ and ME drafted the initial concept for the article together. BP wrote the first full draft. ME provided the revisions and images. BP and $M E$ collaborated on the subsequent revisions. Both $M E$ and $B P$ contributed to the excavation of, and research on, the fossils discussed in this paper. 


\section{ORIGINAL SOURCE ARTICLE}

Hawks, J., Elliott, M., Schmid, P., Churchill, S. E., deRuiter, D. J., Roberts, E. M. et al. 2017. New fossil remains of Homo naledi from the Lesedi Chamber, South Africa. eLife 6:e24232. doi: 10.7554/eLife.24232

\section{REFERENCES}

1. Berger, L. R., Hawks, J., deRuiter, D. J., Churchill, S. E., Schmid, P., Delezene L. K. et al. 2015. Homo naledi, a new species of the genus Homo from the Dinaledi Chamber, South Africa. eLife 4:e09560. doi: 10.7554/eLife.09560

2. Hawks, J., Elliott, M., Schmid, P., Churchill, S. E., deRuiter, D. J., Roberts, E. M. et al. 2017. New fossil remains of Homo naledi from the Lesedi Chamber, South Africa. eLife 6:e24232. doi: 10.7554/eLife.24232

3. Dirks, P. H. G. M., Roberts, E. M., Hilbert-Wolf, H., Kramers, J. D., Hawks, J., Dosseto, A. et al. 2017. The age of Homo naledi and associated sediments in the Rising Star Cave, South Africa. eLife 6:e24321. doi: 10.7554/eLife.24321

4. Johanson, D. C., White, T. D., and Coppens, Y. 1978. A new species of the genus Australopithecus (Primates: Hominidae) from the Pliocene of Eastern Africa. Kirtlandia 28:1-14.

SUBMITTED: 03 September 2019; ACCEPTED: 13 December 2019; PUBLISHED ONLINE: 21 January 2020.

EDITED BY: Michele A. Johnson, Trinity University, United States

CITATION: Peixotto B and Elliott MC (2020) Meet Neo: Your Distant Cousin? Front. Young Minds 7:155. doi: 10.3389/frym.2019.00155

CONFLICT OF INTEREST: The authors declare that the research was conducted in the absence of any commercial or financial relationships that could be construed as a potential conflict of interest.

COPYRIGHT @ 2020 Peixotto and Elliott. This is an open-access article distributed under the terms of the Creative Commons Attribution License (CC BY). The use, distribution or reproduction in other forums is permitted, provided the original author(s) and the copyright owner(s) are credited and that the original publication in this journal is cited, in accordance with accepted academic practice. No use, distribution or reproduction is permitted which does not comply with these terms.

\section{YOUNG REVIEWER}

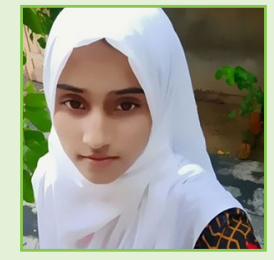

\section{SAMEEN, AGE: 14}

Hello, I am Sameen from Mandi Bahauddin (M.B.Din). My school is very competitive especially in science subjects but I like biology. I like to know about natural processes especially in aquatic species. I love to read newspaper, history books and learn new languages. Besides, I wish to participate in environmental clubs and field trips. I want to study the ecosystems and biology when I grow up. 


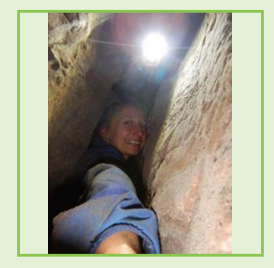

\section{AUTHORS}

\section{BECCA PEIXOTTO}

Becca Peixotto is an archeologist and one of the six original scientists who excavated the bones of Homo naledi in the Rising Star Cave. She is Director of the Center for the Exploration of the Human Journey at the Perot Museum of Nature and Science (Dallas, USA), an Honorary Research Associate at the University of the Witwatersrand, and an AAAS IF/THEN Ambassador. Becca loves using archeology to explore the past and help bring forgotten histories into the present. When not on excavation or in a lab, Becca can be found outdoors skiing, hiking, or climbing. *becca.peixotto@perotmuseum.org

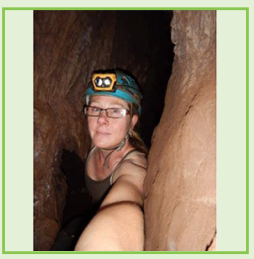

\section{MARINA C. ELLIOTT}

Marina Elliott was also one of the original excavators in the Rising Star Cave. She is a biological anthropologist and archaeologist, interested in how, when, and why humans became the only hominin left on the planet. She is currently a researcher at the University of the Witwatersrand in South Africa, where she continues to excavate and study Homo naledi's remains. Marina is a National Geographic Explorer and Fellow of the Explorers Club. She is passionate about exploration, science, education, and encouraging girls to pursue STEM careers. Like Becca, Marina also loves the outdoors and enjoys hiking, birdwatching, and photography. 